\title{
Apply Ground Theory to Interpret Escapist Experiences in Mudanwan Villa
}

\author{
Tase-Lung Chen ${ }^{1}$, Li-Shiue Gau ${ }^{2}$, Tain-Fung Wu ${ }^{1}$ \\ ${ }^{1}$ Department of Business Administration, Asia University, Taichung, Chinese Taipei \\ ${ }^{2}$ Department of Leisure and Recreation Management, Asia University, Taichung, Chinese Taipei \\ Email: longlong99.tw@yahoo.com.tw, Isgau@asia.edu.tw
}

Received December 2013

\section{Abstract}

The escapist experience requires great immersion and participation. Tourists participating in escapist experiences embark from their daily life and voyage to a specific place and do activities worthy of their time (Oh, Fiore, \& Jeoung, 2007; Pine \& Gilmore, 1999). This study attempted to apply the ground theory to interpret escapist experiences and use Mudanwan Villa in the south of Taiwan as an exemplary place for the escapists to be away from their daily life. "Mudanwan Villa" was used as a key word in the traditional Chinese Google to search for comments left by the villa visitors or other online respondents. Secondary data were then collected from 25 blogs, Pixnets, or discussion forums in travel advisor websites. Content analysis was used, following the grounded data techniques to do the coding and find the themes by an inductive reasoning. The findings provide three propositions. First, temporary residents coming to Mudanwan Villa actively pursue positive experiences such as relaxation and enjoyment. Second, the destination is so unique and special that visitors are willing to pay the high price and endure the long-range transportation difficulties in order to arrive at the villa. Third, the emphasized values associated with the escapist experiences in Mudanwan Villa are detachment, pleasure, wealth, and social recognition (Struch, Schwartz, \& van der Kloot, 2002). The detachment value indicates that visitors in the villa can get away from the daily routine and immerse into the destination $(0 \mathrm{Oh}$, Fiore, \& Jeoung, 2007). The pleasure value implies that the escapists can enjoy the space, experience the environment nearby, and actively use any facilities here in the villa. The wealth value suggests that those people who come to the villa are able to afford the high price. The value of social recognition means that escapist experiences in this unique destination become a status symbol to share with others. This study provides useful information for managers to design a unique experiencescape particularly perhaps to attract independent tourists from Mainland China.

\section{Keywords}

Experiencescape; Experience Economy; Escapist Experience; Mudanwan Villa

\section{Introduction}

After the new tourism law was implemented in Mainland China, the cost of cross-strait tourism products truly 
reflects the payment of reasonable travel expenses. Tourism industry operators also construct better business environment. Nevertheless, the free and independent travelers (FIT) are not subject to the new tourism law, so Taiwan Tourism Bureau aggressively promotes FIT market. Mudanwan Villa is a southern Taiwan's high-priced resort, which is also one of the star products many travel agents recommend to high-class customers. This paper will discuss the application of experience economy in the case of Mudanwan Villa.

\section{Literature Review}

\subsection{Rural Tourism Consumption}

China implemented new tourism law since October 1, 2013. New law regulates all of the domestic and international tourism market. The travel agency shall not arrange any unreasonably cheap tour, nor the agency obtains any rebate through shopping or tourism packages at customers' own expenses. The improper way to get tips is also prohibited.

Nevertheless, the Mainland China's rural tourism industry has to create some star products [1]. Because both Mainland China and Taiwan have the same culture kinship, rural tourism cooperation has been at the forefront of both sides' cooperation. The tourism strategy in China needs to develop more diverse marketing programs. One of them is to pursue escapist experiences in Taiwan, particularly for those free and independent travelers who can afford star products.

From the perspective of customer satisfaction, newspapers' and magazines' information and friends' recommendation are the biggest pushing motivation for consumption, whereas the attributes of products are the biggest factor of pulling motivation for consumption [2]. The attributes which can contribute to the fulfillment of the values of detachment, pleasure, wealth, and social recognition might be able to attract some specific segment of customers.

In addition, the customers generally care about if the sellers provide the satisfaction guarantee. They also care if they have to pay tips or additional cost for the goods or services besides the main cost [3]. Therefore, all in one price without additional tips or cost might demonstrate goodwill of a business to attract tourists. A guarantee to provide a wonderful escapist experiences along with a package price to enjoy all most everything in a suburban villa might be a right tourism design in the age of experience economy.

\subsection{Experience Economy}

Pine II and Gilmore [4-6] proposed “experience economy” concept. They divided human economic development into four stages. The first is "agricultural economy" which produces commodities; the second is "industrial economy" which makes goods; the third is "service economy" which delivers services. The fourth is "experience economy” which stages experiences. An experience can be further divided into four realms: entertainment experience, educational experience, esthetic experience, and escapist experience. Typically the most abundant experience people feel covers all of the four realms, which is called the “sweet spot” (甜蜜点) in the center experience. For example, Disneyland is such a place where children can get to experience the sweet spot. However, the scope of experience is so vast, therefore, that managers should ask themselves: "What specific experience will my company offer?” And by that experience, the company will determine their positioning in the market.

The escapist experience requires great immersion and participation. Tourists participating in escapist experiences embark from their daily life and voyage to a specific place and do activities worthy of their time [5,7]. This study attempted to apply ground theory to interpret escapist experiences and use Mudanwan Villa in the south of Taiwan as an exemplary place for the escapists to be away from their daily life.

\subsection{Grounded Theory}

Grounded theory has its data analysis procedure. First, we interview the participants and record the conversation. Second, the interviews are turned into verbatim transcripts. The third step is to separate interview transcripts into meaningful units, find repeating ideas, and give a code for each unit. Fourth, rewrite the draft as the third person, and categorize the codes. Fifth, label each of the categories, and proceed axial coding. Sixth, extract themes. Finally, choose the encoding original context to form a story line, and develop theoretical propositions through writing stories in a narrative style [8-10]. The guiding principles of grounded theory are to produce quality data with theoretical sense, and analyze data relying on continued comparison and repeated research processes [11]. 


\section{Method}

The research processes can be divided into pre-study stage and formal research process.

\subsection{Pre-Study Stage}

This study adopted a more cost- and time- effective method to collect data through the Internet social media instead of direct interviews. "Mudanwan Villa" was used as a key word in the traditional Chinese Google to search for comments left by the villa visitors or other online respondents. Secondary data were then collected from 25 blogs, Pixnets, or other discussion forums in travel advisor websites. Content analysis was used, following the grounded data techniques.

\subsection{Data Analysis Procedure}

We collected data from the Internet instead of direct interviews. And this is an anonymous research. Grounded theory is used to discuss the escapist experiences in the high-priced resort by the following procedure.

- Blog posts and responses are transferred to the content of transcripts. For example, "juice-bar is a 24 hours service." "Here food is provided in the midnight."

- The verbatim scripts were rewritten into meaningful units and then been categorized, such as a category, "provide good food and wonderful services in the resort."

- Label each of categories. For example, "the resort offers excellent services".

- Identify core themes. Then, theoretical propositions are extracted. For example, one proposition is "providing more customized products and better services will increase guests' willingness to pay higher price."

- The relationships between themes are organized and presented in the form of storytelling narrative. For example, "because Mudawan Villa is a high-priced resort, guests mostly come with better financial and social resources. They endure a long drive in order to temporarily escape from earthly annoyance. Living into this paradise in southern Taiwan, the visitors feel relaxed in the separated area and enjoy the services and facilities in the resort."

\section{Results}

Content analysis was used, following the grounded data techniques to do the coding and find the themes by an inductive reasoning. The findings provide three propositions.

\subsection{Proposition $P 1$}

First, temporary residents coming to Mudanwan Villa actively pursue positive experiences such as relaxation and enjoyment. Buyers usually focus on comparison of price and pursuit of function. But guests in Mudanwan Villa focus on the escapist experiences and enjoyment. For example, one visitor said, "The escapist experience in natural aesthetics away from the urban noise let me enjoy a complete relaxation for a weekend. If you want to be very close to the nature and also enjoy attentive services in a resort, Mudanwan Villa is definitely a great choice.”

\subsection{Proposition P2}

Second, like a star product, the destination is so unique, scarce, and special that visitors are willing to pay the high price and endure difficulties of the long-distance transportation in order to arrive at the villa. One guest recalled that "although the price is not cheap nor the transportation is easy, but the experience is very valuable." Another guest mentioned that "even compared with very famous Sunmoon Lake Lalu Hotel, the Villas provides even warmer atmosphere and better hospitality and becomes customers' favorite paradise.”

\subsection{Proposition P3}

Third, the emphasized values associated with the escapist experiences in Mudanwan Villa are detachment, pleasure, wealth, and social recognition [12]. The detachment value indicates that visitors in the villa can get away from the daily routine and immerse into the destination [7]. For example, one couple recalled that "this trip totally belongs to my husband and me in this lovely resort—Mudanwan Villa. And thank grandmother to take care 
of our little daughter so we can relax, empty our mind, and enjoy here.”

The pleasure value implies that the escapists can enjoy the space, experience the environment nearby, and actively use any facilities here in the villa. For example, one visitor mentioned that "what a great environment! This is really a good place for a holiday to stay where the package contains everything including very nice amenities, good food and services.”

The wealth value suggests that those people who come to the villa are able to afford the high price. Many respondents agreed that "Mudanwan Villa is one of the most expensive resorts in Taiwan." The value of social recognition means that escapist experiences in this unique destination become a status symbol to share with others. A response to a visitor's experience in the Villa said that "I admire those rich people who can afford to stay in so expensive place [Mudanwan Villa].” A premium price for a product with an equivalent quality seems to create prestige in customers' mind and produce admiration in others' eyes [13].

\section{Conclusion}

Applying the ground theory, this study uses Mudanwan Villa in the south of Taiwan as an exemplary place for the escapists to be away from their daily life to interpret escapist experiences. The findings provide three propositions, which are useful information for managers to design a unique escape experience particularly perhaps to attract independent tourists from Mainland China. Based on the results of the study, we are able to interpret escapist experiences realized through staying at a high-priced resort. However, most collected secondary data in this study were from participants who had consumed in Mudanwan Villa before and posted tourist accommodation feelings and comments on the websites. One could argue that the sample might not be the representative of general consumers of the segment in the high-prices resorts. This would be a limitation of the current study and there should be a caution not to over generalize the research findings. In the future, we recommend conducting a larger empirical study with a more diverse sample along with diverse data collection such as interviews.

\section{References}

[1] Jin, J.H. (2013) Jen-Son Cheng, a Scholar of Rural Tourism from Taiwan, Said: The Rural Tourism Patterns in Mainland China Are too Monotonous (大陆乡村旅游模式过于单一). http://fz.ifeng.com/zt/dijiujielvyoubolanhui/lvbohui/detail_2013_09/07/1198344_0.shtml

[2] Pine II, B.J. and Gilmore, J. H. (1998) Welcome to the Experience Economy. Harvard Business Review, 97-105.

[3] Tsaur, S.H. and Wang, C.H. (2009). Tip-Collection Strategies, Service Guarantees, and Consumer Evaluations of Group Package Tours. Journal of Travel Research, 11, 523-534.

[4] Pine II, B.J. and Gilmore, J.H. (1998). Welcome to the Experience Economy. Harvard Business Review, July-August, 97-105.

[5] Pine II, B.J. and Gilmore, J.H. (1999). The Experience Economy. Harvard Business School Press, Boston.

[6] Pine II, B.J. and Gilmore, J.H. (2011). The Experience Economy. Harvard Business School Press, Boston.

[7] Oh, H., Fiore, A.M. and Jeoung, M. (2007). Measuring Experience Economy Concepts: Tourism Applications. Journal of Travel Research, 46, 119-132.

[8] Su, C. (2012) A Typology of Content Analysis for Business and Management Academic Periodical in Taiwan by Grounded Theory. NPUST Humanities and Social Sciences Research, 6, 1-23.

[9] Auerbach, C.F. and Silverstein, L.B. (2003). Qualitative Data: An Introduction to Coding and Analysis. New York University, New York.

[10] Gau, L.S. and James, J.D. (2013). A Ten-Value-Type Framework Associated with Spectator Sports-A Qualitative Inquiry. Sage Open (May-June).

[11] Oh, H., Fiore, A.M. and Jeoung, M. (2007) Measuring Experience Economy Concepts: Tourism Applications. Journal of Travel Research, 46, 119-132.

[12] Struch, N, Schwartz, S.H. and van der Kloot, W.A. (2002). Meanings of Basic Values for Women and Men: A Cross-Cultural Analysis. Personality and Social Psychology Bulletin, 28, 16-28.

[13] Bagwell, L.S and Bernheim, B.D. (1996). Veblen Effects in a Theory of Conspicuous Consumption. American Economic Review, 86, 349-373. 